\title{
In-Hive Miticides and their Effect on Queen Supersedure and Colony Growth in the Honey Bee (Apis mellifera)
}

\section{Juliana Rangel ${ }^{1 *}$ and David R Tarpy $\mathbf{2}^{2,3}$}

${ }^{1}$ Department of Entomology, Texas A\&M University, 2475 TAMU, College Station, Texas 77843-2475, USA

${ }^{2}$ Department of Entomology, North Carolina State University, Campus Box 7613, Raleigh, NC 27695, USA

${ }^{3}$ Keck Center for Behavioral Biology, North Carolina State University, Campus Box 7613, Raleigh, NC 27695, USA

\begin{abstract}
Honey bees (Apis mellifera) contribute an estimated $\$ 200$ billion annually to the global economy, primarily through crop pollination. Despite their importance, the number of managed honey bee colonies continues to decline. Recent surveys have shown that colony losses are attributed in great part to problems associated with the ectoparasitic mite Varroa destructor, and with issues related to poor queen quality (particularly premature queen replacement), which often result in decreased colony productivity and increased risk of mortality. We aimed to investigate how sublethal exposure to beekeeper-applied miticides affects honey bees at both the individual (queen) and colony levels. We did so by comparing the growth (comb built, brood produced, food stored, and worker population), queen supersedure rates, and winter survival probabilities of colonies that were headed by queens that were raised in either miticide-laden or miticide-free beeswax cups then housed in hives that were either treated with miticides or left untreated. Contrary to our prediction, we found that treated colonies headed by queens raised in miticide-laden beeswax built significantly more worker and drone comb, and stored more food, than any other colony treatment. We did not, however, observe any other significant effect of colony treatment on the amount of brood production, worker population size, queen supersedure rate, or colony winter survival. Thus, we failed to observe a direct negative effect of miticide exposure at the colony level. More studies are needed to further test the potentially detrimental synergistic effects of in-hive miticides on honey bee health at the colony level.
\end{abstract}

Keywords: Apis mellifera; Coumaphos; Honey bee queen; Taufluvalinate; Supersedure; Varroa destructor

\section{Introduction}

Pollinator health continues to be a topic of major interest worldwide, particularly due to the rapid population decline of both native and managed pollinator species [1-5]. The honey bee (Apis mellifera) is arguably the most important insect pollinator of major agricultural crops, contributing an estimated $\$ 200$ billion to the global economy annually, $\$ 17$ billion in the United States alone [6-8]. Despite their importance to agriculture, the number of managed honey bee colonies available for pollination has decreased steeply in the last decade, threatening the production of many bee-dependent crops nationwide $[9,10]$. This decline has been attributed to the many health issues facing honey bees today-problems caused by pathogens and parasites, the use of in-hive chemicals to treat for these ailments, the exposure of colonies to agricultural pesticides and genetically modified crops during foraging, and poor beekeeping practices [11-13]. Moreover, recent surveys from several commercial beekeeping operations across the United States reported that the most common causes of colony losses included poor queen quality, problems associated with the parasitic mite Varroa destructor, poor nutrition and starvation, and other less impactful factors $[14,15]$. The combined information from these reports suggests that the increased use of in-hive chemicals to combat Varroa mites has coincided with a general decrease in colony health that may lead to increased colony losses.

For the last two decades, Varroa mites have been controlled in the United States primarily with two in-hive miticides: the pyrethroid tau-fluvalinate (Apistan') and the organophosphate coumaphos (Checkmite $\left.+^{\circ}\right)$. These chemicals are administered in colonies as miticide-impregnated strips placed between frames of brood, and kept in the hive for several weeks [16]. Despite their efficacy when first approved for use in apiaries, mites quickly developed resistance to both fluvalinate [17-20] and coumaphos [21]. Continuous application of these lipophilic chemicals has led to their permanent presence in the wax comb [22-25], especially in commercial beekeeping operations $[26,27]$. Even though therapeutic concentrations of fluvalinate and coumaphos have been reported to have low toxicity to bees $[28,29]$-likely because of the bees' rapid ability for detoxification by cytochrome P450 monooxygenases [30,31]-several studies have linked the use of these miticides with a decrease in honey bee colony health (see above). Likewise, the increased use of these miticides to control Varroa mites has coincided with an increase in problems relating to poor queen quality [22,32-35]. In fact, beekeepers continue to report issues with lower queen lifespan due to rapid supersedure-when the workers in a honey bee colony replace their mother queen with a new sister queen-as well as the inability of colonies to naturally raise new queens in a timely fashion [36-38].

Numerous studies have explored the effects of either fluvalinate or coumaphos on the reproductive quality of honey bees. For example, persistent application of fluvalinate has been shown to decrease the sexual competitiveness and size of drones [39-41]. Likewise, colonies treated with high doses of fluvalinate have resulted in disturbed oviposition and rapid queen losses [22], low queen weight [32], and poor queen rearing success [34]. Similarly, prolonged persistence of coumaphos in a colony, even at low doses, has been shown to cause low

${ }^{*}$ Corresponding author: Rangel J, Department of Entomology, Texas A\&M University, 2475 TAMU, College Station, TX77843, USA, Tel: 979-8445-1074; Fax: 979-845-6305; E-mail: jrangel@tamu.edu

Received March 21, 2016; Accepted May 28, 2016; Published May 31, 2016

Citation: Rangel J, Tarpy DR (2016) In-Hive Miticides and their Effect on Queen Supersedure and Colony Growth in the Honey Bee (Apis mellifera). J Environ Anal Toxicol 6: 377. doi:10.4172/2161-0525.1000377

Copyright: $\odot 2016$ Rangel J, et al. This is an open-access article distributed under the terms of the Creative Commons Attribution License, which permits unrestricted use, distribution, and reproduction in any medium, provided the original author and source are credited. 
queen body weight [32,33,35], low queen ovary weight [32], low queenrearing success [33], as well as high queen mortality [32]. This evidence demonstrates that fluvalinate and coumaphos use have potentially damaging effects to honey bee health, particularly individual drones and queens.

Honey bee queens are produced commercially by 'grafting' (the physical transfer of worker larvae from worker cells into plastic or beeswax cups). Once larvae are grafted, the cups are positioned vertically inside queenless colonies where a large population of young nurse workers feed royal jelly to the queen-destined larvae until they pupate and their wax cells get sealed [42]. One study of commercial queen rearing operations found higher accumulations of fluvalinate and coumaphos in queen cells compared to the surrounding beeswax, which suggests that queen larvae are differentially exposed to those chemicals during development [32]. The aforementioned studies have looked at the effects of either fluvalinate [29,32] or coumaphos [32-35] on honey bee reproductive health. But to date, no studies have looked at the combined effects of both miticides on the health of honey bee queens and the colonies they head, which is a critical consideration knowing that both compounds are ubiquitous within managed beehives in the US [27] and have been shown to exhibit negative synergetic effects on individual bees $[31,43]$.

In this study, we attempted to address the potential issues associated with exposure to combinations of tau-fluvalinate and coumaphos by both, developing honey bee queens, and new colonies headed by these queens. We did so by establishing new colonies that were headed by queens reared in either miticide-laden or miticide-free beeswax cups, and then housed in hives that were either treated with those same miticides or left untreated. We subsequently measured several variables of colony growth, as well as queen supersedure events and winter survivorship, to determine if exposing colonies to miticides in the queen-rearing environment, the hive environment, or both, has an effect on overall queen and colony health. Doing so will identify a potentially important mechanism of colony losses and a means to mitigate them.

\section{Methods}

\section{Study site and bees}

This study was conducted at the Lake Wheeler Honey Bee Research Facility of North Carolina State University in Raleigh, North Carolina $\left(35^{\circ} 43^{\prime} 27^{\prime \prime},-78^{\circ} 40^{\prime} 33^{\prime \prime}\right)$. All the colonies from which we created packages of bees were headed by naturally mated 'Italian' queens (Apis mellifera ligustica). We used a single source colony to graft all experimental queens, and thus, all queens were sisters to each other.

\section{Beeswax queen cups}

We used standard queen-rearing plastic cups that we coated with molten beeswax obtained from Kenya (Burt's Bees, Morrisville, NC), a country where honey bees are not treated with miticides for Varroa control [44]. Moreover, because of the extremely low tolerance for inhive and other pesticides in their products, cosmetic companies maintain very strict standards for purchasing pesticide-free beeswax. We coated each plastic cup with $\sim 240 \mathrm{mg}$ of molten beeswax, covering the bottom, inner, and outer sides of the cup. To create miticide-free beeswax cups, we simply submerged each cup into the miticide-free molten wax. To create beeswax cups impregnated with miticides, we added $20.4 \mathrm{mg}$ of fluvalinate (PESTANAL' analytical standard, Sigma-Aldrich, St. Louis, $\mathrm{MO}$ ) and $9.4 \mathrm{mg}$ of coumaphos (PESTANAL analytical standard, Sigma-Aldrich, St. Louis, MO) to $100 \mathrm{~g}$ of miticide-free beeswax to obtain a total miticide concentration of $204 \mathrm{ppm}$ of fluvalinate and 94 ppm of coumaphos in the wax. These total concentrations were chosen from the reported maximum concentrations of these two miticides found in wax comb samples obtained from over 250 beekeeping operations recently surveyed across the United States [27].

\section{Queen rearing}

On 16 May 2011, we reared experimental queens from one-day-old worker larvae from a single source colony following standard queenrearing grafting methods [45]. Briefly, we transferred each larva into a beeswax-coated plastic cup that was either miticide-free or impregnated with fluvalinate and coumaphos in the concentrations mentioned above. We then placed the larvae grafted in the miticide-laden beeswax cups into one "swarm box" colony (i.e., a queenless colony with nurse workers to raise new queens), and the larvae grafted in the miticidefree beeswax cups into a separate swarm box colony. These queen rearing colonies, as well as all initial colonies in the study population, were not treated with either compound for mite control and thus had minimal (albeit probably non-zero) levels of both miticide. Once the mature queen cells were sealed, they were individually placed inside small "nucleus" colonies containing about 1,000 workers, where each virgin queen was allowed to emerge from her cell, mate naturally, and eventually commence oviposition. The mated queens were labeled with a paint mark on the thorax and were finally introduced into new experimental colonies (see below) on 9 June 2011. We raised a total of 40 naturally mated experimental queens, half of them reared in miticide-free beeswax cups and the other half reared in miticide-laden beeswax cups.

\section{Establishment of new experimental colonies}

On 9 June 2011, we created 40 packages of bees from larger, unrelated source colonies that had never been treated with fluvalinate or coumaphos for mite control. Each package of bees was queenless and contained a standard $2 \mathrm{lbs}$ of bees, or about 7,000 individuals (1.0 $\mathrm{kg}$ of bees contains approximately 7,700 individuals) [46]. We then shook the bees from each package into a 10-frame hive box containing alternating frames with either partial or full wax foundation. Full-wax foundation only promotes worker comb construction, whereas partialwax foundation enables the workers to construct either worker or drone foundation depending on the colony's needs. A total of 40 tenframe hives bodies were used, 20 of which were newly constructed and thus had never been exposed to any in-hive chemical contamination, whereas the other 20 hives had been used in apiaries for several years, and thus, might have had residual levels of chemical pesticides. Likewise, we used either newly-purchased frames or used, rewired frames, placing them into new or used hive bodies, respectively. We then introduced one of the mated experimental queens into each newly established colony. The 40 hives were established in the same apiary and placed in alternating order by treatment.

\section{Miticide treatment of experimental hives}

The 20 colonies established in new beekeeping equipment were left untreated throughout the experiment. The other 20 colonies housed in used beekeeping equipment were treated with miticides after colony establishment. To treat colonies, we placed half a strip of Apistan ${ }^{\circledR}$ (Bayer Corporation, Shawnee Mission, KS) and half a strip of Checkmite $+{ }^{\mathbb{B}}$ (Bayer Corporation, Shawnee Mission, KS) between brood frames following the therapeutic dosages suggested by the manufacturers. We treated colonies twice, once on 22 June 2011 and then again on 8 July 2011, removing the strips two weeks after each 
application. In summary, we created a total of 40 experimental hives, 10 each belonging to one of four experimental groups: colonies headed by queens raised in miticide-free beeswax cups and housed in new untreated hives (Treatment 1); colonies headed by queens reared in miticide-free beeswax cups and housed in hives treated with fluvalinate and coumaphos strips (Treatment 2); colonies headed by queens that were raised in miticide-laden beeswax cups and housed in untreated hives (Treatment 3); and colonies headed by queens that were raised in miticide-laden beeswax cups and housed in treated hives (Treatment 4 ).

\section{Measurements of colony growth}

To test the effects of miticides in queen-rearing and hive environment on colony growth, we took monthly measurements from each experimental colony from 9 June 2011, the day of colony establishment (Day 0), through 14 October 2011, the last day of data collection (Day 127). We did so by using a gridded wooden frame containing 1361 -in $^{2}$ squares to measure several characteristics of colony growth, as described previously [47]. We began by estimating the total area of newly built worker and drone comb, the total area of sealed worker and drone brood, and the total area of stored food (including honey and pollen). We then estimated worker population size by uniformly sampling each frame in the hive, counting the number of bees in 20 evenly spaced $1-$ in $^{2}$ squares on both sides of the frame, extrapolating the resulting counts to estimate the total worker population covering the entire frames, and adding to those values an estimate of the number of workers found on the inner walls of the hive.

\section{Measures of queen supersedure and winter survival}

To test the effects of queen-rearing and hive environment on queen supersedure and winter survival rates, we recorded any episode of queen supersedure in newly established colonies. We defined a successful supersedure event as the presence of a laying, unmarked queen and the absence of the marked, experimental queen. Likewise, we monitored colony survival throughout the season and into the early spring the following year by listening for bees buzzing in the hive to determine which colonies were still alive on 1 March 2012 (Day 266 after colony establishment).

\section{Statistical analysis}

To test the effect of colony treatment on colony growth, we performed a generalized linear mixed model using the GLIMMIX procedure on the SAS statistical software (SAS Institute Inc., Cary, NC). Because the measured variables (e.g., amount of comb built, amount of brood produced, amount of food stored, and adult worker population size) were taken continually from the same colonies over time, we built the model to include the fixed effects of queen-rearing environment (miticide-laden vs. miticide-free beeswax cups to raise queens), hive environment (hives treated with miticides vs. untreated hives), time (day after colony establishment), and their appropriate interactions. F-tests were used to test the null hypothesis of no effect of colony treatment on colony growth measurements. In all cases, the interactions between the effects of the queen-rearing environment, the hive environment, and time were not significant and thus pair-wise differences in the means of each treatment were not analyzed. Data for colony growth measurements are presented as the mean \pm S.E.M.

Furthermore, we performed a Fisher's exact test to determine whether colony treatment had an effect on the likelihood that a colony superseded its mother queen (JMP v10.0, SAS Institute Inc., Cary, NC). We also conducted a logistic regression test (JMP v10.0, SAS Institute Inc., Cary, NC) to determine whether colonies in a specific treatment group exhibited statistically higher overwintering survival probabilities than colonies in other treatment groups. The levels of significance of all statistical tests was set at $\alpha=0.05$.

\section{Results}

We grafted larvae into a total of 90 miticide-free beeswax cups, and 90 miticide-laden beeswax cups. Of these, nurse workers initiated the queen-rearing process in 74 miticide-free cups ( $82 \%$ queen-rearing initiation success), and 51 miticide-laden cups (56\% initiation success). Of the queen cups that got initiated by workers, 34 queens raised in miticide-free beeswax cups, and 26 queens raised in miticide-laden beeswax cups, emerged from their cells and mated successfully. We should strongly caution, however, that these data are not directly comparable to previous estimates of grafting success, as the two treatment groups of queens were reared in separate colonies to avoid cross-contamination. Our purpose here was to obtain viable, laying queens rather than assess the process by which they were raised.

The effects over time of exposure of the miticides fluvalinate and coumaphos in either the queen-rearing environment, the hive environment, or both, on the growth patterns of newly established honey bee colonies are shown in Figure 1. Colonies headed by queens raised in miticide-laden beeswax cups and housed in hives that were treated with miticides constructed on average twice as much worker comb (Figure 1a; $\mathrm{F}_{1,40}=4.48, \mathrm{P}=0.04$ ) and $\sim 10$ times more drone comb (Figure $1 \mathrm{~b} ; \mathrm{F}_{140}=8.72, \mathrm{P}=0.009$ ), and stored approximately 60 percent more honey and pollen (Figure $1 \mathrm{c} ; \mathrm{F}_{1,16}=4.147, \mathrm{P}=0.05$ ), compared to any other colony treatment. There was no significant effect of miticide exposure in the queen-rearing environment or hive environment on the production of worker brood (Figure 1d; $\mathrm{F}_{1,16}=2.57, \mathrm{P}=0.13$ ), the production of drone brood (Figure 1e; $\mathrm{F}_{1,18}=1.30, \mathrm{P}=0.27$ ), or the population of adult workers present in the hive (Figure 1e; $\mathrm{F}_{1,16}=1.82$, $\mathrm{P}=0.41$ ). Thus overall, we found that for some parameters measured, but not all, colonies that were exposed to miticides in the queen-rearing and hive environment grew larger and stronger throughout the season than those headed by any other colony treatment.

We found no significant positive effect of colony treatment on the winter survival probability of newly established colonies. Of the 40 colonies that were established on 9 June 2011 (i.e., 10 colonies per treatment group), a total of only 5 colonies were alive by 1 March 2012. Of these, 2 colonies were headed by queens raised in miticide-free beeswax cups and housed in untreated hives, 2 colonies were headed by queens raised in miticide-laden beeswax cups and housed in untreated hives, and one colony was headed by queens raised in miticide-laden beeswax cups and housed in treated hives. None of the colonies headed by queens raised in miticide-free beeswax cups an housed in treated hives survived through the winter. By 14 October 2011 (Day 127), almost twice as many colonies (7 vs. 4) housed in untreated hives were still alive compared to colonies housed in treated hives (Figure 2). But overall, survivorship of colonies decreased steadily and similarly over time for all treatment groups, and colony treatment had no significant effect on the probability of colony winter survival $\left(\chi^{2}=0.06 ; \mathrm{P}=0.80\right)$.

Finally, we observed a total of seven supersedure events after colony establishment on 9 June 2011 (Table 1). However, there was no significant effect of colony treatment on the likelihood that the workers in a colony superseded the queen ( 2 -tailed test, $\mathrm{P}=0.428$ ). Interestingly, no supersedure events were recorded after 17 August 2011, indicating that colonies replaced their mother queen within just a few weeks after colony establishment. 
Citation: Rangel J, Tarpy DR (2016) In-Hive Miticides and their Effect on Queen Supersedure and Colony Growth in the Honey Bee (Apis mellifera) J Environ Anal Toxicol 6: 377. doi:10.4172/2161-0525.1000377


Figure 1: Growth patterns for honey bee colonies established on 9 June 2011 (Day 0), each belonging to one of four treatments based on whether their colonies were headed by queens that were raised in either miticide-laden or miticide-free beeswax cups, and their hives were treated with miticides or left untreated. Upon establishment, each colony received a standard $2 \mathrm{lbs}$ of bees, or approximately 6,950 workers. Colony growth was monitored through 14 October 2011 (Day 127 ). See "Methods" for details on colony set up. Data are presented as the mean \pm S.E.M.

\begin{tabular}{|c|c|c|c|c|c|}
\hline \multirow{3}{*}{$\begin{array}{l}\text { Date of queen } \\
\text { supersedure }\end{array}$} & \multirow{3}{*}{$\begin{array}{l}\text { Days after colony } \\
\text { establishment }\end{array}$} & \multicolumn{4}{|c|}{ No. of queen supersedure events observed per colony type } \\
\hline & & Treatment 1 & Treatment 2 & Treatment 3 & Treatment 4 \\
\hline & & $\begin{array}{l}\text { Miticide-free queen cup, } \\
\text { untreated hive }\end{array}$ & $\begin{array}{c}\text { Miticide-free queen cup, } \\
\text { treated hive }\end{array}$ & $\begin{array}{l}\text { Miticide-laden queen cup, } \\
\text { untreated hive }\end{array}$ & $\begin{array}{l}\text { Miticide-laden queen cup, } \\
\text { treated hive }\end{array}$ \\
\hline 8 July 2011 & 29 & 1 & 0 & 2 & 1 \\
\hline 3 August 2011 & 55 & 0 & 0 & 0 & 1 \\
\hline 17 August 2011 & 69 & 1 & 0 & 0 & 1 \\
\hline \multicolumn{2}{|c|}{ Total supersedures/colony type } & 2 & 0 & 2 & 3 \\
\hline
\end{tabular}

Table 1: Episodes of queen supersedure (i.e., when the workers in a honey bee colony replace their mother queen with a new sister queen) in colonies that belonged to one of four treatment groups based on whether their hives were treated with the miticides fluvalinate and coumaphos (following label therapeutic application protocols), and whether they were headed by queens that were reared in miticide-laden or miticide-free beeswax cups (see "Methods" for details). All colonies were established on 9 June 2011 and queen supersedure events were monitored through 14 October 2011. 


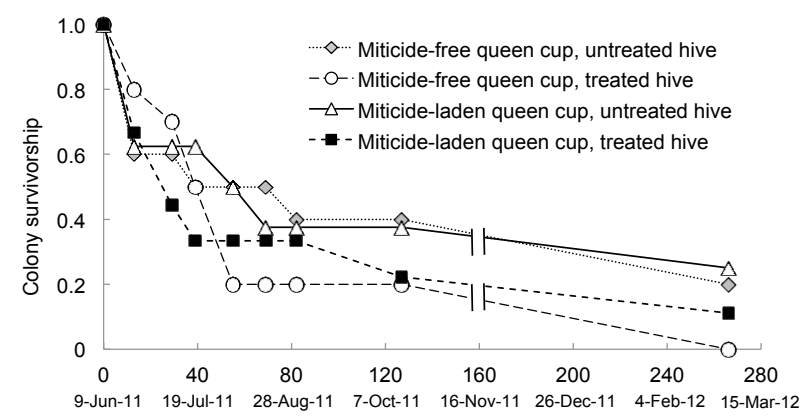

Day after colony establishment

Figure 2: Colony survivorship curves for honey bee colonies established on 9 June 2011 (Day 0). Each new colony belonged to one of four treatment groups, based on (a) whether their hive were treated with the miticides fluvalinate and coumaphos, or was left untreated, and (b) weather it was headed by a queen raised in miticide-laden, or miticide-free beeswax cup. On day zero, each colony contained a standard $2 \mathrm{lbs}$ of bees, or approximately 6,950 (see "Methods" for details on how the new colonies were originally established). The broken lines indicate that no survivorship data was collected in the winter. Winter survivorship was assessed on 1 March 2012 (Day 266). Dates below the days after colony establishment are provided for reference only.

\section{Discussion}

Our study found that, upon establishment, honey bee colonies headed by queens raised in miticide-laden beeswax cups and housed in hives that were treated with therapeutic dosages of the miticides fluvalinate and coumaphos, built more worker and drone comb, and stored more food resources, than colonies in any other experimental treatment group. However, we did not find a significant effect of a colony's exposure to miticides on either the amount of worker and drone brood produced or in the total number of workers present in the colony. These results are similar to those found by Westcott and Winston [47], who did not find any differences in colony weight gain, brood survival, sealed brood area, post-emergence bee weight, or worker foraging activity, between untreated colonies and those colonies treated with therapeutic dosages of fluvalinate. Varroa levels were not measured in this study because we were interested in testing the miticides' sublethal effects on colony growth and queen supersedure, not their therapeutic effects for mite control. In hindsight, however, having measured Varroa levels throughout the experiment would have provided useful information on whether the use of miticides decreased mite populations leading to healthier, more productive colonies.

Even though we did not find a negative effect of miticides at the colony level, exposure to miticides during development severely affects honey bee health at the individual (queen) level. While it would have been useful to analyze the "miticide-free" wax used to coat the experimental queen cups to ensure that such wax did not contain traces of chemical residues, we remain confident that they contained biologically insignificant levels. Even so, the results between the treatment groups are relative to each other regardless of the initial conditions. Prior work exposing adult bees to fluvalinate did not affect worker longevity within a few days after exposure, but it caused high worker mortality at least 24 days after the bees' original exposure to the miticide [29]. Furthermore, several studies have reported a decrease in several aspects of queen quality after exposure to miticides during development $[22,32-34,39,40]$. In a recent study conducted by Rangel and Tarpy (in review), honey bee queens that were raised in miticideladen beeswax cups showed significantly lower sperm counts, lower sperm viability, and higher mating frequency, compared to queens reared in miticide-free beeswax cups. Our current data, however, suggest that these effects at the individual level do not seem to be reflected at the colony level, at least during the first year of colony establishment.

One of our main objectives was to test the effect of miticides on the likelihood of queen supersedure, predicting higher rates of supersedure in colonies headed by queens raised in miticide-laden beeswax cups and housed in hives treated with miticides. Curiously, we found no evidence of either, which is not consistent with earlier studies. Previous studies have suggested that supersedure can occur because the queen is failing due to disease $[48,49]$ or injury $[50,51]$ but not grafting age [52], insemination volume [53], or oviposition rate [54]. Nonetheless, because queen supersedure has become increasingly problematic in commercial beekeeping operations [36-38], it remains a high priority to identify the causes of premature supersedure. Previous studies have reported differences in the chemical composition of the queen mandibular gland [52,55-58] and the Dufour's gland [59] based on the queen's reproductive state and insemination quantity, therefore it would be very telling if there were significant differences in queen pheromones between queens raised in miticide-free versus miticideladen beeswax cups, and if so, to what degree workers inside the colony perceive these differences.

This study is the first to look at the combined long-term effects of both coumaphos and fluvalinate on the growth, queen supersedure rate, and wintering survival of honey bee colonies. Despite previous reports of detrimental effects of these miticides at the individual level, our results indicate that exposure of these miticides does not seem to cause detrimental problems at the colony level. In general, chemical treatment to control Varroa continues to be widely practiced by beekeepers, given that, if left untreated, persistent mite infestations generally lead colonies to succumb to "parasitic mite syndrome," which weakens them point of collapse, and even death [60]. Nevertheless, the use of fluvalinate and coumaphos appears to be on the decline due to the mite's wide-spread resistance to these chemicals [16] and thus alternative methods for Varroa control have been used successfully $[61,62]$. Therefore, a novel avenue of research regarding the effects of alternative mite-control methods on queen survival and colony growth should be pursued. Thus, future studies should focus not only on the sublethal effects of commonly-used miticides, but also the effects of alternative Varroa-control methods on colony productivity and longevity over several years, which are the true indicators of overall colony health.

\section{Acknowledgements}

We are indebted to Jennifer Keller and Marcus Hill for helping us collect data in the field. We are grateful to Burt's Bees for donating the beeswax pellets used to coat plastic queen-rearing cups. We also thank Dr. Consuelo Arellano for her statistical advice. Funding was provided to JR by the US National Science Foundation Postdoctoral Research Fellowship in Biology (Award number 1002465), and to DRT by the NC Department of Agriculture and Consumer Services and Grant number 2007-02281 from the National Research Initiative of the USDA Cooperative State Research, Education and Extension Service.

\section{References}

1. Thomas JH, Telfer MG, Roy DB, Preston CD, Greenwood JJD, et al. (2004) Comparative losses of British butterflies, birds, and plants and the global extinction crisis. Science 303: 1879-1881.

2. Biesmeijer JC, Roberts SPM, Reemer M, Ohlemüller $R$, Edwards $M$, et al. (2006) Parallel declines in pollinators and insect-pollinated plants in Britain and the Netherlands. Science 313: 351-354.

3. vanEngelsdorp D, Underwood R, Caron D, Hayes J (2007) An estimate of managed colony losses in the winter of 2006-2007: A report commissioned by the Apiary Inspectors of America. Am Bee J 147: 599-603. 
Citation: Rangel J, Tarpy DR (2016) In-Hive Miticides and their Effect on Queen Supersedure and Colony Growth in the Honey Bee (Apis mellifera) J Environ Anal Toxicol 6: 377. doi:10.4172/2161-0525.1000377

Page 6 of 7

4. Cameron SA, Lozier JD, Strange JP, Koch JB, Cordes N et al. (2011) Patterns of widespread decline in North American bumble bees. Proc Natl Acad Sci USA 108: 662-667.

5. Burkle LA, Marlin JC, Knight TM (2013) Plant-pollinator interactions over 120 years: loss of species, co-occurrence, and function. Science 339: 1611-1615.

6. Morse RA, Calderone NW (2000) The value of honeybee pollination the United States. Bee Cult 128: 1-15.

7. Gallai N, Salles JM, Settele J, Vassiére BE (2009) Economic valuation of the vulnerability of world agriculture confronted with pollinator decline. Ecol Econ 68: 810-821

8. Calderone NW (2012) Insect pollinated crops, insect pollinators and US agriculture: trend analysis of aggregate data for the period 1992-2009. PLoS One 7: e37235.

9. Aizen MA, Harder LD (2009) The global stock of domesticated honey bees is growing slower than agricultural demand for pollination. Curr Biol 19: 915-918.

10. Rucker RR, Thurman WN, Burgett M (2012) Honey bee pollination markets and the internalization of reciprocal benefits. Am J Agr Econ 94: 956-977.

11. Oldroyd BP (2007) What's killing American honey bees? PLoS Biol 5: e168.

12. Johnson RM, Ellis MD, Mullin CA, Frazier M (2010) Pesticides and honey bee toxicity-USA. Apidologie 4: 312-331.

13. Food and Agricultural COST Action FA0803 (2012) Prevention of honey bee colony losses (COLOSS) Final Report.

14. vanEngelsdorp D, Hayes J Jr, Underwood RM, Pettis J (2008) A survey of honey bee colony losses in the U.S., fall 2007 to spring 2008. PLoS One 3: e4071.

15. vanEngelsdorp D, Hayes J Jr, Underwood RM, Pettis J (2010) A survey of honey bee colony losses in the United States, Fall 2008 to Spring 2009. J Apicult Res 49: 7-14.

16. Rosenkranz P, Aumeier P, Ziegelmann B (2010) Biology and control of Varroa destructor. J Invertebr Pathol 103 Suppl 1: S96-119.

17. Lodesani M, Colombo M, Spreafico M (1995) Ineffectiveness of Apistan treatment against the mite Varroa jacobsoni Oud in several districts of Lombardy (Italy). Apidologie 26: 67-72.

18. Elzen PJ, Eischen FA, Baxter JB, Pettis J, Elzen GW, et al. (1998) Fluvalinate resistance in Varroa jacobsoni from several geographic locations. Am Bee $J$ 138: $674-686$.

19. Elzen PJ, Baxter JR, Spivak M, Wilson WT (2000) Control of Varroa jacobson Oud resistant to fluvalinate and amitraz using coumaphos. Apidologie 3: 437441.

20. United States Federal Register (2000) Coumaphos: pesticide tolerance for emergency action.

21. Elzen PJ, Westervelt D (2002) Detection of coumaphos resistance in Varroa destructor in Florida. Am Bee J 142: 291-292.

22. Sokol R (1996) The influence of a multimonth persistence of Fluwarol in a hive of a honey bee colony. Med Weter 52: 718-720.

23. Fries I, Wallner K, Rosencranz P (1998) Effects on Varroa jacobsoni from acaricides in beeswax. J Apicult Res 37: 85-90.

24. Wallner K (1999) Varroacides and their residues in bee products. Apidologie 30: $235-248$

25. Martel AC, Zeggane S, Aurieres C, Drajnudel P, Faucon JP, et al. (2007) Acaricide residues in honey and wax after treatment of honey bee colonies with Apivar (R) or Asuntol (R) 50. Apidologie 38: 534-544.

26. Frazier M, Muli E, Conklin T, Schmehl D, Torto B, et al. (2010) A scientific note on Varroa destructor found in East Africa; threat or opportunity? Apidologie 41: 463-465.

27. Mullin CA, Frazier M, Frazier JL, Ashcraft S, Simonds R, et al. (2010) High levels of miticides and agrochemicals in North American apiaries: implications for honey bee health. PLoS One 5: e9754.

28. Stoner A, Wilson WT, Moffett JO (1984) Effects of long term feeding of low doses of fenvalerate or fluvalinate in sucrose syrup on honey bees Apis mellifera in standard-sized field colonies. J Georgia Entomol So 19: 490-498.
29. Pettis JS, Wilson WT, Shimanuki H, Teel PD (1991) Fluvalinate treatment and worker honey bees (Apis mellifera L) and effects on subsequent mortality queen acceptance and supersedure. Apidologie 22: 1-7.

30. Johnson RM, Wen Z, Schuler MA, Berenbaum MR (2006) Mediation of pyrethroid insecticide toxicity to honey bees (Hymenoptera: Apidae) by cytochrome P450 monooxygenases. J Econ Entomol 99: 1046-1050.

31. Johnson RM, Pollock HS, Berenbaum MR (2009) Synergistic interactions between in-hive miticides in Apis mellifera. J Econ Entomol 102: 474-479.

32. Haarmann T, Spivak M, Weaver D, Weaver B, Glenn T (2002) Effects of fluvalinate and coumaphos on queen honey bees (Hymenoptera: Apidae) in two commercial queen rearing operations. J Econ Entomol 95: 28-35.

33. Collins AM, Pettis JS, Wilbanks R, Feldlaufer MF (2004) Performance of honey bee (Apis mellifera) queens reared in beeswax cells impregnated with coumaphos. J Apicult Res 43: 128-134.

34. Pettis JS, Collins AM, Wilbanks R, Feldlaufer MF (2004) Effects of coumaphos on queen rearing in the honey bee Apis mellifera. Apidologie 35: 605-610.

35. Collins AM, Pettis JS (2013) Correlation of queen size and spermathecal contents and effects of miticides exposure during development. Apidologie 44 351-356.

36. Webster TC (1998) Queen problems-Survey results. Bee Cult 126: 40-41.

37. Sanford MT (2001) Queen problems. Apis Newsletter, University of Florida, Gainesville, USA.

38. vanEngelsdorp D, Tarpy DR, Lengerich EJ, Pettis JS (2013) Idiopathic brood disease syndrome and queen events as precursors of colony mortality in migratory beekeeping operations in the eastern United States. Prev Vet Med 108: 225-233.

39. Rinderer TE, De Guzman LI, Lancaster VA, Delatte GT, Stelzer JA (1999) Varroa in the mating yard: I. The effects of Varroa jacobsoni and Apistan on drone honey bees. Am Bee J 139: 134-139.

40. Sylvester HA, Watts RP, De Guzman LI, Stelzer JA, Rinderer TE (1999) Varroa in the mating yard: II. The effects of Varroa and fluvalinate on drone mating competitiveness. Am Bee J 139: 225-227.

41. Johnson RM, Dahlgren L, Siegfried BD, Ellis MD (2013) Effect of in-hive miticides on drone honey bee survival and sperm viability. J Apicult Res 52: 88-95.

42. Laidlaw HH, Page R (1997) Queen Rearing and Bee Breeding. Wicwas Press Cheshire.

43. Dahlgren L, Johnson RM, Siegfried BD, Ellis MD (2012) Comparative toxicity of acaricides to honey bee (Hymenoptera: Apidae) workers and queens. J Econ Entomol 105: 1895-1902.

44. Frazier M, Mullin C, Frazier J, Ashcraft S (2008) What have pesticides got to do with it? Am Bee J 148: 521-523.

45. Laidlaw HH, Eckert JE (1962) Queen Rearing. University of California Press, Los Angeles.

46. Mitchell C (1970) Weights of workers and drones. Am Bee J 110: 468-469.

47. Westcott LC, Winston ML (1999) Chemical acaricides in Apis mellifera (Hymenoptera: Apidae) colonies; do they cause nonlethal effects? Can Entomol 13: 363-371

48. Farrar CL (1947) Nosema losses in package bees as related to queen supersedure and honey yields. J Econ Entomol 40: 333-338.

49. Furgala B (1962) The effect of the intensity of Nosema inoculum on queen supersedure in the honey bee, Apis mellifera Linnaeus. J Ins Pathol 4: 429-432.

50. Wedmore EBA (1942) Manual of Beekeeping. Arnold Press, London.

51. Cook VA (1968) Severe clipping of queens' wings increases supersedure rate. $\mathrm{N}$ Zeal Beekeep 30: 32.

52. Rangel J, Keller JJ, Tarpy DR (2013) The effects of honey bee (Apis mellifera L.) queen reproductive potential on colony growth. Insect Soc 60: 65-73. 
Citation: Rangel J, Tarpy DR (2016) In-Hive Miticides and their Effect on Queen Supersedure and Colony Growth in the Honey Bee (Apis mellifera). J Environ Anal Toxicol 6: 377. doi:10.4172/2161-0525.1000377

53. Niño EL, Malka O, Hefetz A, Teal P, Hayes J, et al. (2012) Effects of honey bee (Apis mellifera L.) queen insemination volume on worker behavior and physiology. J Ins Physiol 58: 1082-1089.

54. Butler CG (1957) The process of queen supersedure in colonies of honeybees (Apis mellifera Linn.). Insect Soc 4: 211-223.

55. Richard FJ, Tarpy DR, Grozinger CM (2007) Effects of insemination quantity on honey bee queen physiology. PLoS One 2: e980.

56. Kocher SD, Richard FJ, Tarpy DR, Grozinger CM (2008) Genomic analysis of postmating changes in the honey bee queen (Apis mellifera). BMC Genomics 9: 232.

57. Kocher SD, Richard FJ, Tarpy DR, Grozinger CM (2009) Queen reproductive state modulates pheromone production and queen-worker interactions in honey bees. Behav Ecol 20: 1007-1014.
58. Kocher SD, Grozinger CM (2011) Cooperation, conflict, and the evolution of queen pheromones. J Chem Ecol 37: 1263-1275.

59. Richard FJ, Schal C, Tarpy DR, Grozinger CM (2011) Effects of instrumenta insemination and insemination quantity on Dufour's gland chemical profiles and vitellogenin expression in honey bee queens (Apis mellifera). J Chem Ecol 37 : 1027-1036.

60. Boecking O, Genersch E (2008) Varroosis-the ongoing crisis in beekeeping. J Verbrauch Lebensm 3: 221-228.

61. Calderone NW (1999) Evaluation of formic acid and a thymol-based blend of natural products for the fall control of Varroa jacobsoni (Acari: Varroidae) in colonies of Apis mellifera (Hymenoptera: Apidae). J Econ Entomol 92: 253-260.

62. Delaplane KS, Berry JA, Skinner JA, Parkman JP, Hood AM (2005) Integrated pest management against Varroa destructor reduces colony mite levels and delays treatment threshold. J Apicult Res 44: 157-162. 